\title{
In Vitro regeneration of Plumbago zeylanica Linn through embryo culture
}

\author{
Smita S. Chaudhari ${ }^{1}$, G.S.Chaudhari ${ }^{2}$ \\ ${ }^{1}$ Department of Botany,Dr.A.G.D.Bendale Mahila Mahavidyalaya ,Jalgaon, India \\ ${ }^{2}$ Principal, Post Graduate College of Science, Technology and Research, Jalgaon, India
}

\begin{abstract}
Plumbago zeylanica Linn is listed as Threatened Medicinal Plant and is widely used in traditional systems of medicine. Embryos from seeds of Plumbago zeylanica Linn were cultured on M.S. Medium and M.S. Medium supplemented with natural complex-tomato juice (30\%). Embryos on both the media showed successful germination and seedlings were developed within eight weeks. Regenerated seedlings transferred in thermocol cup containing sterile (autoclaved) mixture of sand, vermicompost \& soil (1:1:1) for hardening showed $93.75 \%$ survival rate. The regenerated seedlings were successfully acclimatized in green house with100\% result and then $100 \%$ transplantation success was achieved under natural atmospheric conditions. The present study provide efficient, simplified, economic protocol for rapid in vitro regeneration of Plumbago zeylanica Linn
\end{abstract} Keywords: Embryo, In Vitro Regeneration, Medicinal Plant, M.S. Medium, Plumbago zeylanica Linn.

\section{Introduction}

Plumbago zeylanica Linn is perennial plant of family plumbaginaceae .It is Commonly called as White leadwort, White plumbago , Ceylon leadwort, Safed chitrak .It is evergreen shrub and enjoys an important place in traditional medicine since ancient time. It is used in many preparations of Ayurvedic as well as Unani system[1]

\section{चित्रकोSनलनामा च पाठी व्यालस्तथोषणः। चित्रक कटुकः पाके वहिनकृत्पाचनो लघुः॥} रूक्षोष्णो ग्रहणीकुष्ठशोथार्शः कृमिकासनुत्। वातश्लेष्महरो ग्राही वातघ्नः श्लेष्मपित्तहत्त

The tincture of root bark of Plumbago zeylanica Linn is antiperiodic ,sudorific .Milky juice is applied in scabies and ulcers . [3] [4] Roots are abortifacient, vesicant, antidiarrhoeal, appetizing, digestive . It is useful in anasarca ,piles ,dyspepsia . [3] [4] It is also useful in epilepsy, hysteria ,rheumatic affections, obesity, purigo. [3] It is used in leprosy. [4] Vaghabhata and Susruta praised it as bitter tonic . [5] The plant is used as vulnerary in New Caledonia. The roots are used as an enema to cure piles in the Gold Coast. [4] The roots stimulates the secretion of urine , bile and has stimulant action on the nervous system. [6]

Because of its use in various diseases, the plant is continuously collected from nature without replanting . Seeds are produced in large number but propagation through seed is unreliable due to poor seed quality ,erratic germination and seedling mortality under natural field conditions (Chaplot et al 2006) [6]It is listed as threatened medicinal plant(Mittal and Sharma 2010) [7] and in future likely to be endangered if not conserved and propagated properly.

Review of earlier studies reveals that maximum protocols developed for in vitro regeneration of Plumbago zeylanica L. were from explants like nodal segments [6] [8] [9] [10] [11] [12] [13] , leaves[6] [12] ,segments of internodes[8] ,shoot tips[8].Only one record of regeneration through embryo culture by Idayat T. Gbdamosi and A . Eguyomi was found . [9] The present study was undertaken to establish a rapid simplified method of in vitro regeneration through embryo culture to supplement natural propagation.

\section{Materials And Methods}

\subsection{Collection of seeds}

Seeds of Plumbago zeylanica Linn .cultivated in house garden were selected and dried in shade . Damaged and shrunken seeds were discarded and healthy uniform seeds were selected.

\subsection{Soaking of seeds}

Seeds were soaked in sterile distilled water for 24 hours [14]. 


\subsection{Surface sterilization}

The seeds were washed thoroughly in running tap water for 30 minutes. The seeds are rinsed in D.W containing a drop of Tween 20. Then washed repeatedly in sterile D.W. for 4-5 times. Then surface sterilization with $70 \%$ ethyl alcohol for 1 min followed by repeated washing with sterile D.W. was done .Then again the material is surface sterilized by $0.1 \%$ mercuric chloride for 8 minutes Seeds were rinsed properly 3-4 times with sterile D.W. [8] [15]

\subsection{Culture medium}

Murshige-Skoog medium was used for embryo culture. Murshige-Skoog medium was with 3\% sucrose $\& 0.8 \%$ agar. $\mathrm{P}^{\mathrm{H}}$ of medium is adjusted to $5.8[16]$ prior to autoclaving. Medium was autoclaved at 15 pounds pressure for 20 minutes. M .S .medium supplemented with natural complex- tomato juice (30\%) [17] was also used .

\subsection{Inoculation of embryo}

Embryos from surface sterilized seeds were excised with the help of sterile blade without causing injury to embryo. These excised embryos were cultured aseptically in test tubes containing medium .All these operations were carried out aseptically in Laminar Air Flow Cabinet.

\subsection{Culture Conditions}

The cultures were incubated in tissue culture room at $25 \pm 2{ }^{\circ} \mathrm{C}$ with photoperiod of 16 hours.

\subsection{Hardening}

Regenerated seedlings were removed from culture medium.Washed thoroughly in sterile distilled water to remove medium. Then these plantlets were directly transferred to thermocol cup containing sterile (autoclaved) mixture of sand, vermicompost \& soil (1:1:1). Thermocol cups were kept in culture room for 2 weeks. [10] Then they were transferred to larger earthen pots containing sand, and garden soil (1:4) \& kept in green house for one month \& then transferred to normal field conditions.

\section{Results And Discussion}

Embryos showed higher percentage of germination on M .S.medium as compared with M .S. medium supplemented with natural complex- tomato juice (30\%).Percentage germination of embryo on different media is as presented in Table 1. Two cotyledonary leaves start to separate on $5^{\text {th }}-6^{\text {th }}$ day of culture and later they become green within 2-3 days. Number of leaves start to increase from $18^{\text {th }}$ days of culture. Seedlings were completely developed within eight weeks of culture .Table 2 shows growth of root and shoot of seedlings developed on M.S. Medium. These seedlings when transferred in thermocol cup containing sterile (autoclaved) mixture of sand, vermicompost \& soil (1:1:1) for hardening show $93.75 \%$ survival rate. Regenerated seedlings were then transferred in larger earthen pots \& kept in green house. They show $100 \%$ survival and then they were transferred in natural field conditions with $100 \%$ success.

Seedlings developed on M.S.medium and M.S.medium supplemented with natural complex- tomato juice (30\%) showed differences in nature of roots and leaves. These differences are shown in Table 3.

Idayat T. Gbdamosi and A .Eguyomi ( 2010) cultured embryos on M. S. medium supplemented with $\mathrm{NaH}_{2} \mathrm{PO}_{4} \cdot \mathrm{H}_{2} \mathrm{O}(170 \mathrm{mg} / \mathrm{l}), 2,4 \mathrm{D}(0.5 \mathrm{mg} / \mathrm{l})$ and different combinations of NAA and BAP and also on NPK basal media supplemented with different concentrations of Citrus sinensis juice. The present protocol uses M.S. medium without addition of any plant hormones. Developed protocol is simple and help to minimize experimental cost. The regenerated plants did not show any morphological variation compared to mother plant

\section{Figures And Tables}

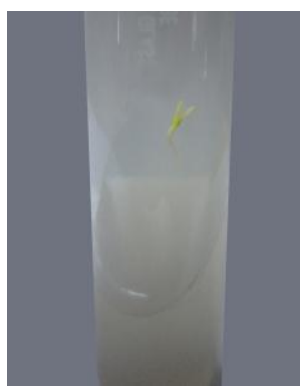

(a)

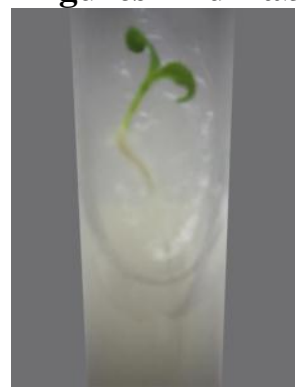

(b)

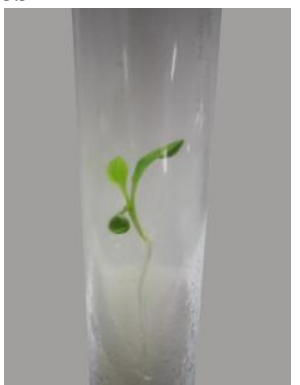

(c) 


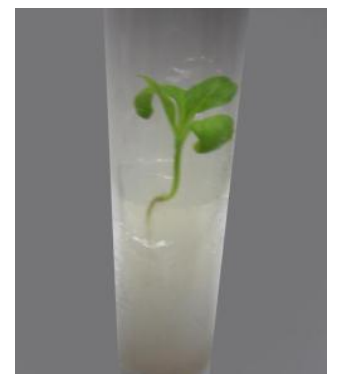

(d)

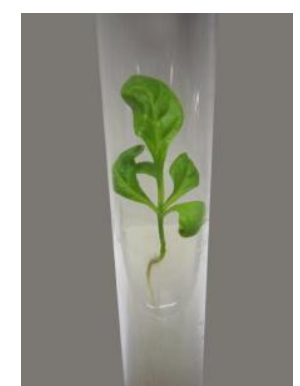

(e)

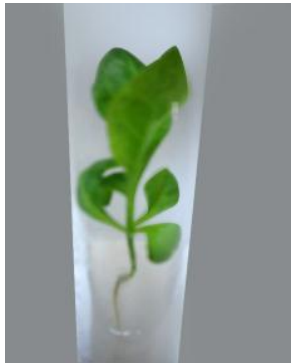

(f)

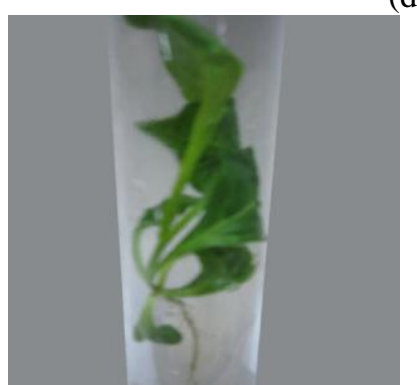

(g)

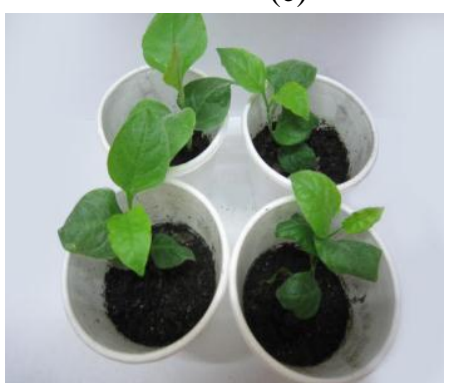

(h)

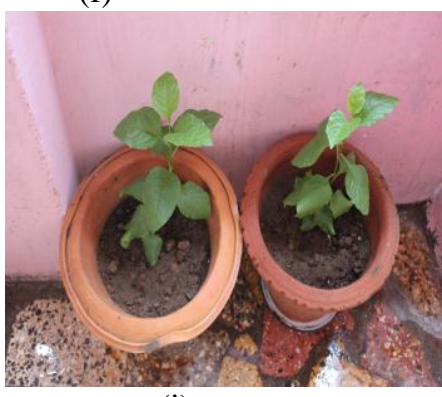

(i)

Figure 1. Different Developmental Stages Of Embryo Culture on M.S. Medium (a) Cotyledonary leaves separating at $6^{\text {th }}$ day of culture (b) Two leaves stage at $11^{\text {th }}$ day of culture(c) Three leaves stage at $18^{\text {th }}$ day of culture (d) Four leaves stage at $27^{\text {th }}$ day of culture(e) Five leaves stage at $31^{\text {st }}$ day of culture(f) Six leaves stage at $35^{\text {th }}$ day of culture (g) Seedling before hardening (h) Hardening (i) Transplanted regenerated plants

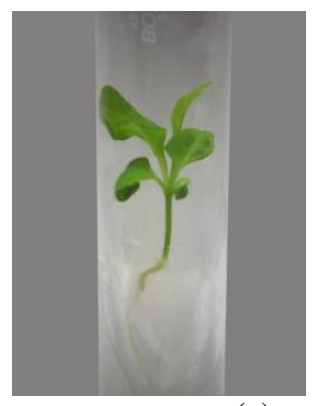

(a)

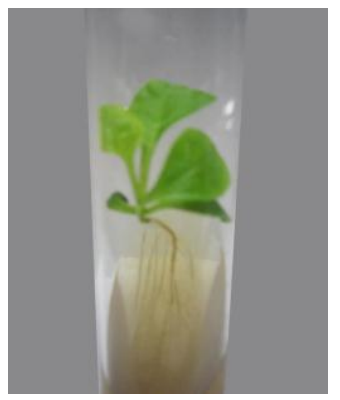

(b)

Figure 2. Effect of different media on nature of root \& leaves (a)seedling developed on M.S. medium (b) seedling developed on M.S. medium supplemented with natural complex-Tomato juice(30\%)

Table1.PERCENTAGE GERMINATION OF EMRRYO ON DIFFERENT MEDIA

\begin{tabular}{|c|c|c|c|}
\hline Sr.No. & Type of Medium & \% Germination & \%Callus formation \\
\hline 1 & M .S. Medium & 100 & 0 \\
\hline 2 & M.S .Medium supplemented with natural complex- \\
tomato juice (30\%) & 92.86 & 0 \\
\hline
\end{tabular}

Table 2.ROOT AND SHOOT LENGTH OF SEEDLINGS DEVELOPED IN EMBRYO CULTURE ON M.S.MEDIUM

\begin{tabular}{|c|c|c|c|}
\hline Sr. No. & No .of Days of culture & $\begin{array}{c}\text { Root Length } \\
(\mathrm{cm})\end{array}$ & $\begin{array}{c}\text { Shoot length } \\
(\mathrm{cm})\end{array}$ \\
\hline 1 & 10 & $3.23 \pm 0.64$ & $0.6 \pm 0.14$ \\
\hline 2 & 12 & $3.83 \pm 0.79$ & $0.82 \pm 0.15$ \\
\hline 3 & 14 & $4.04 \pm 0.72$ & $1.08 \pm 0.13$ \\
\hline 4 & 16 & $4.67 \pm 0.54$ & $1.39 \pm 0.06$ \\
\hline 5 & 18 & $5.19 \pm 0.81$ & $2.15 \pm 0.34$ \\
\hline 6 & 20 & $5.48 \pm 0.76$ & $2.53 \pm 0.33$ \\
\hline 7 & 22 & $5.91 \pm 0.93$ & $2.75 \pm 0.43$ \\
\hline 8 & 24 & $6.18 \pm 0.98$ & $2.89 \pm 0.40$ \\
\hline 9 & 26 & $6.59 \pm 0.93$ & $3.21 \pm 0.36$ \\
\hline 10 & 28 & $6.97 \pm 0.99$ & $3.42 \pm 0.29$ \\
\hline
\end{tabular}




\begin{tabular}{|c|c|c|c|}
\hline 11 & 30 & $7.39 \pm 1.02$ & $3.6 \pm 0.32$ \\
\hline 12 & 32 & $7.68 \pm 0.93$ & $3.90 \pm 0.17$ \\
\hline 13 & 34 & $8.04 \pm 0.71$ & $4 \pm 0.28$ \\
\hline 14 & 36 & $8.22 \pm 0.74$ & $4.48 \pm 0.48$ \\
\hline 15 & 40 & $8.44 \pm 0.73$ & $4.69 \pm 0.45$ \\
\hline 16 & 42 & $8.82 \pm 0.67$ & $5.06 \pm 0.24$ \\
\hline
\end{tabular}

The results are mean \pm S.D. of three experiments, each with 3 replications

Table3. EFFECT OF DIFFERENT MEDIA ON NATURE OF ROOT \& LEAVES

\begin{tabular}{|c|c|c|c|}
\hline Sr.No. & Medium & Roots & Leaves \\
\hline 1 & M.S. Medium & $\begin{array}{c}\text { Thin ,less } \\
\text { branched ,short, } \\
\text { dirty white in colour }\end{array}$ & Barrow \& Longer \\
\hline 2 & $\begin{array}{c}\text { M.S. medium supplemented with } \\
\text { natural complex-Tomato juice (30\%) }\end{array}$ & $\begin{array}{c}\text { Thick, extensively } \\
\text { Branched ,long, } \\
\text { darker }\end{array}$ \\
\hline
\end{tabular}

\section{Conclusion}

Present study provide reproducible, simplified protocol for direct regeneration of plant Plumbago zeylanica Linn with high frequency. This ensure sustainability and easy availability of plant for treatment of various diseases.

\section{Acknowledgement}

The authors are grateful to University Grants Commission, New Delhi for financial assistance and Dr. S. S. Rane, Principal Dr. A .G .D .Bendale Mahila Mahavidyalaya ,Jalgaon for providing necessary infrastructure for research.

\section{References}

[1] P. Bhaskar, Encyclopedia of Ayurvedic Medicinal Plants Vol 2 (Delhi , Mangalam Publications,2011)

[2] Krishnachandra Chunekar,Bhavaprakashnighantu (Varanasi , Chaukhambha Bharati Academy,2010)

[3] Chttterjee Asima , Satyesh Chandra Pakrashi, The Treatise of Indian Medicinal Plants Vol 4(New Delhi, National Institute of Science , Communication and Information Resources,CSIR,2003)

[4] Kirtikar, Basu, Indian Medicinal plants (Dehradun ,Uttaranchal, Oriental Enterprises , 2001)

[5] Herbalcureindia,CITRAKA (Plumbago zeylanica), http;//www.herbalcureindia.com/herbs/citraka.htm

[6] B.B. Chaplot, A.M.Dave, Y.T. Jasrai , A valued medicinal plant-Chitrak (Plumbago zeylanica Linn):Successful plant regeneration through various explants and field performance, Plant Tissue Culture \& Biotech 16(2), 2006, 77-84.

[7] Vineet Mittal , S.K.Sharma, An in vitro antimicrobial activity of callus and root extracts of Plumbago zeylanica Linn in various test micro-organisms , International Journal of Pharmaceutical Sciences Review and Research Vol 5(2), 2010,1-4

[8] Iyyakkannu Sivanesan and Byoung Ryong Jeong, Micropropagation of Plumbago zeylanica L., African Journal of Biotechnology , Vol 8 (16) 2009,3761-3768.

[9] Idayat T. Gbdamosi and A . Eguyomi, Micropropagation of Plumbago zeylanica L. (Plumbaginaceae)in Ibadan,Southwestern Nigeria, Journal of Medicinal plant Research Vol 4 (4) ,2010 ,293-297.

[10] Satyajit Kanungo , Shanti Lata Sahoo , Rajani Kanta Sahu, Development of simplified protocol for in vitro propagation of valuable medicinal plant Plumbago zeylanica Linn through nodal explants found in Odisha, India. Journal of Medicinal plant Research Vol 6 (13), 2012,2627-2632.

[11] S.Antony Ceaser,M. Ayyanar, S.Ignacimuthu ,An Improved Micropropagation Protocol for Plumbago zeylanica L. An Important Medicinal Plant , Asian Journal of Biological Sciences 6 (4) , 2013 , 214-220

[12] S.L.Patidar, M.K.Tripathi,G. Tiwari ,R.S.Chundawat, A.Pandey,H. Patidar, G.N. Pandey, In vitro Micropropagation of Plumbago zeylanica L. through nodal segment and leaf explants ,Plant Cell Biotehnology and Molecular Biology 14(3\&4) :XX-XX

[13] G.R. Rout ,C .Saxena ,S. Samantaray \& P.Das, Rapid Clonal propagation of Plumbago zeylanica Linn,Plant Growth Regulation 28 ,1999,1-4.

[14] Jalja S. Menon, S.Prasannakumari Amma, E.V. Nybe , Stimulation of seed germination of white flowered leadwort ( Plumbago zeylanica Linn ) Journal of Tropical Agriculture.39,2001, 180-181.

[15] Nandini Mohan, Saeid Nikdad, Geeta Singh, Studies on seed germination and embryo culture of Jatropha curcas L.under in vitro conditions . Research Article, Biotechnol .Bioinf . Bioeng.Vol 1 (2) 2011, 187-194

[16] V.K. Khanna , Plant Tissue Culture Practice (Ludhiana, Kalyani Publishers, 2003)

[17] Misra S.P. , Plant Tissue Culture ( New Delhi , Ane Books Pvt. Ltd. , 2009) 